\title{
MEMORIA Y DEMOCRACIA. UNA RELACIÓN INCIERTA
}

Elizabeth Jelin (elijelin@gmail.com)

CONICET-IDES

Argentina

Los procesos ligados a las manifestaciones públicas de memoria tienen al menos dos etapas: una de iniciativas de instalación de marcas territoriales y conmemoraciones, que responde a una demanda de un grupo humano de emprendedores que intentan inscribir ciertos sentidos a fechas o a lugares, fisicos o simbólicos; y una segunda etapa, que también aparece en el momento de la instalación como una intención "pedagógica", remite a la significación de la conmemoración para el resto de la gente y para las generaciones futuras. Este texto trabaja sobre este segundo tema, que toma como eje el horizonte de futuro, el impacto o efecto de la memoria en los cambios sociopolíticos que se quieren ver plasmados. El objetivo es poner en cuestión algunos de los supuestos y sobre entendidos básicos implícitos en ese "deber de memoria": la relación entre memoria y justicia, entre memoria y democracia, y entre preservación-conservación y transmisión. Para ello, se presentan algunos procesos institucionales estatales, procesos en el plano simbólico y en el ámbito de la educación y la transmisión. No es el objetivo presentar un análisis exhaustivo de todos los procesos y dimensiones de cambio en estos ámbitos, sino plantear algunas situaciones que permiten repensar y plantear preguntas nuevas sobre la relación entre memoria y democracia.

Palabras clave: Memoria, justicia, democracia.

\section{MEMORY AND DEMOCRACY.ANUNCERTAINRELATIONSHIP}

Processes linked to public expression of memory follow two stages: the first consists of the initiatives to commemorate and erect territorial markers. Usually this responds to the demands of people that attempt to inscribe certain meanings in dates and symbolic or physical sites. The second, which tends to coincide in time with the first, has a pedagogical intention, aiming to transmit the meaning of the commemoration to others who have not lived through the experience as well as to future generations. This paper deals with this second theme that takes the future horizon as the focus, looking at the effects of memory on desired sociopolitical changes. The aim is to question some of the basic assumptions implicit in the "duty to remember": the relation ship between memory and justice, between memory and democracy, between preserving and transmitting. The paper presents institutional-state processes, processes in the symbolic and cultural realm, and those regarding education and transmission. The objective is not to present an exhaustive rendering of all the processes of change in these realms; rather to use some examples in order to rethink and ask new questions about the link between memory and democracy.

Keyword: Memory, justice, democracy. 
Las marcas institucionales, territoriales y simbólicas explícitamente ancladas en el pasado reciente de violencia y represión han proliferado en el mundo contemporáneo. Se trata de expresiones producidas por actores y movimientos sociales diversos y por políticas estatales que responden a las demandas de estos actores sociales; algunas veces surgen de iniciativas gubernamentales propias. La justificación de estas manifestaciones es diversa, e incluye procesos individuales y grupales (expresión y elaboración de sufrimientos vividos, solidaridad con víctimas, homenaje a quienes ya no están) y argumentaciones y creencias que ligan el "deber de memoria" con la construcción de futuros más democráticos, sin violencias. En este segundo caso, el énfasis está puesto en la preocupación por los legados y por la transmisión a las nuevas generaciones, lo que podríamos llamar la dimensión "pedagógica” de la memoria.

Existe una extensa bibliografia que analiza el primer tipo de proceso y su justificación, necesariamente ligado a los acontecimientos pasados -homenajes a víctimas, reconocimiento simbólico de sufrimientos, demandas de reparaciones económicas y simbólicas, expresiones de solidaridad, pedidos de justicia-. Se trata de iniciativas de familiares y víctimas, de grupos de solidaridad, que reclaman de diversa manera el reconocimiento y el homenaje -a través de memoriales, monumentos y otras marcas territoriales, de investigaciones históricas y recolección de testimonios o de archivos documentales-. También entra en este proceso la elaboración artística y performática realizada por múltiples actores y a través de múltiples medios como el cine, la literatura, el teatro, las artes plásticas, etc. En suma, las memorias del pasado reciente, de sufrimiento y violencia política, actúan como estímulo de un sinnúmero de rituales, producciones culturales y de búsquedas de interpretaciones y explicaciones.

Todos los procesos de conmemoración, de marcas territoriales y recuperaciones, de consagración de fechas, de cambio de nombre a las calles o de iniciativas de este tipo son actos conmemorativos que tienen al menos dos etapas.Viene primero la etapa de su instalación, que responde a una demanda de un grupo humano de emprendedores que intentan inscribir ciertos sentidos a fechas o a lugares, fisicos o simbólicos. Nunca sucede por azar, sino que se trata de la presencia de sujetos activos en un escenario político del presente en el que luchan, aunque es un presente ligado a acontecimientos pasados. Aun cuando los promotores y emprendedores traten por todos sus medios de imponerlos, los sentidos nunca están cristalizados o inscriptos en la piedra del monumento o en el texto grabado en la placa. Estos no son más que un soporte, lleno de ambigüedades, para el trabajo subjetivo y para la acción colectiva, política y simbólica, de otros actores específicos, que lo harán en otros escenarios y en otras 
coyunturas históricas. En la primera etapa, entonces, se trata de iniciativas sociales importantes y significativas, especialmente para quienes las promueven.

Hay luego una segunda etapa, que también aparece en el momento de la instalación como una intención "pedagógica”, que remite a la significación de la conmemoración para el resto de la gente y para las generaciones futuras. Insisto: nadie puede asegurar que el sentido que quisieron darle los iniciadores de la conmemoración se mantenga en el futuro. A menos que haya un grupo humano que active permanentemente el sentido de esa conmemoración y promueva que otros tomen esa bandera, muchas de las políticas de conmemoración en la ciudad se pueden convertir en mobiliario urbano habitual, o puede cobrar sentidos no previstos, otros. Además del acto de homenaje, toda marca ligada al pasado tiene inscripta en sí misma un horizonte de futuro, una idea de que lo que se inscribe hoy (en relación con el ayer) carga un mensaje para mañana, una intención de intervenir para que el futuro sea mejor, para que no repita los errores y horrores del pasado.

Este texto trabaja sobre este segundo tema, que toma como eje el horizonte de futuro, el impacto o efecto de la memoria en los cambios sociopolíticos que se quieren ver plasmados. El objetivo es poner en cuestión algunos de los supuestos y sobreentendidos básicos implícitos en ese "deber de memoria": la relación entre memoria y justicia, entre memoria y democracia, y entre preservación-conservación y transmisión. Al analizar estas relaciones, el trabajo se propone reubicar el tema de la memoria en el contexto de estructuras y procesos sociales más amplios, ligados centralmente a la persistencia de múltiples desigualdades sociales y a la relación memoria - presente político.

En el momento fundacional de las transiciones, hubo una consigna clara que, dicho de distintas maneras, se repetía en lugar tras lugar: "nunca más". Implícita en esta consigna está la idea de que hacia el futuro, es necesario crear las condiciones para que la violencia vivida no se repita "nunca más". ¿Cómo interpretar esta consigna? ¿Qué es lo que no hay que repetir? ¿De qué condiciones se estaba hablando? Un primer "deber de memoria" surge en ese momento, ligado a la idea de "recordar para no repetir". Pero, ¿qué era lo que había que "recordar para no repetir"? Puesto de manera tajante, ¿la violencia o las condiciones que le dieron origen?

En muchos casos, el argumento vinculó la memoria de la violencia y las atrocidades con la construcción de sistemas democráticos, y la transmisión de esas memorias como fundantes de una ciudadanía democrática en el futuro. En realidad, hace 20 o 30 años, en el momento de las transiciones postdictatoriales en el Cono Sur, 
teníamos la certeza de que había una relación necesaria entre la activación de las memorias del pasado represivo y los procesos de institucionalización democrática. Esa certeza se convirtió en un slogan y tanto el mundo académico como el mundo de activistas y de políticos/as progresistas lo dieron por supuesto. Me refiero a la idea de que hay que recordar para no repetir, de que solo recordando y solo teniendo una política activa en relación con el pasado dictatorial se puede construir democracia hacia el futuro. Este era el supuesto y el motor del compromiso político que estaba por detrás de aquel proyecto. Pasados los años, este supuesto se convirtió en una gran pregunta: ¿una política activa de memoria es condición necesaria para la construcción democrática?Y cuando digo construcción democrática me refiero a diferentes ámbitos y niveles de la vida pública, incluyendo las propuestas pedagógicas.

Vuelvo a la pregunta, ¿qué es lo que hay que recordar? ¿Qué aspectos específicos de la democracia están ligados a la activación de las memorias del pasado dictatorial y de violencia? Propongo desarticular y descomponer la relación entre memoria y democracia, y explorar en qué aspectos concretos de la democracia opera la activación de memorias del pasado dictatorial. Para ello, analizaré algunos procesos institucionales estatales, procesos en el plano simbólico y en el ámbito de la educación y la transmisión. No es el objetivo presentar un análisis exhaustivo de todos los procesos y dimensiones de cambio en estos ámbitos, sino presentar algunas situaciones que permiten repensar y plantear preguntas nuevas sobre la relación entre memoria y democracia.

\section{Procesos institucionales estatales}

Una mirada sobre la transición post franquista en España indica que frente al silencio y represión de los recuerdos de la Guerra Civil durante los cuarenta años de franquismo, hubo una explosión de recuerdos de la Guerra Civil en testimonios, múltiples producciones culturales -en el cine, en la literatura, en la música-. En términos institucionales, estos recuerdos se manifestaron en una forma especial de "nunca más": que no se repita el tipo de enfrentamiento como el de la Guerra Civil. En verdad, se hizo muy poco o nada en cuanto al reconocimiento estatal de las violencias dictatoriales del pasado reciente, o de las atrocidades y sufrimientos de la Guerra Civil de cuarenta años antes. El Estado no llevó adelante ninguna política de justicia o de memoria que pusiera a las víctimas en el centro de la escena (recordemos que el paradigma de los derechos humanos recién se empezaba a plantear en el espacio internacional de los años setenta). No hubo juicios, e inclusive no se implementó una política de remoción de los símbolos del franquismo, que hoy en día se piensa y se promueve internacionalmente bajo el rótulo de "justicia transicional". 
En la superficie, parecería que se trató de una transición anclada en el silencio, o aun en la promoción del olvido. Sin embargo, como muestra Aguilar Fernández (1996), no se trató de olvido sino de aprendizaje político. Los actores políticos de la transición optaron por elaborar una manera de construcción institucional anclada en un "no repetir": lo que no había que repetir eran las condiciones institucionales en que se agudizó el conflicto que desembocó en la Guerra Civil. "La contienda, como memoria, estaba presente cuarenta años después de su término y... había dejado huellas indelebles en la sociedad española. Sin embargo, lejos de representar todo ello un obstáculo para la convivencia armónica de la sociedad, acabó siendo el acicate necesario para facilitar las múltiples negociaciones que fueron precisas en la transición” (Aguilar Fernández, 1996:22). En realidad, en España la política de memoria es muy reciente: la ley de memoria histórica es de 2007. La discusión sobre el pasado, sus memorias y sus secuelas es un fenómeno del presente, cuando pasaron más de setenta años desde la Guerra Civil y casi cuarenta desde la muerte de Franco. Sin embargo, nadie duda de que la democracia española esté consolidada.

España es un caso testigo que pone una luz de alerta sobre la relación entre el qué del recuerdo y la consolidación institucional democrática. Algo análogo podría decirse de Chile, donde las fuerzas políticas democráticas armaron -y mantuvieron durante décadas- una "concertación” entre Democracia Cristiana y Socialismo que hubiera resultado impensable antes. El intento fue el de no repetir la confrontación política pre golpe, reemplazando la confrontación por la concertación.

En los dos casos, los actores políticos apostaron a una construcción del nuevo orden que no fomente el tipo de conflictos del pasado. Es decir, en España o en Chile, el diseño institucional en el momento de la transición estuvo armado sobre la base de una memoria para no repetir, no la violencia sino las condiciones institucionales dentro de las cuales se generó el campo de violencia. No se trató de decir un "nunca más" solamente a las dictaduras, sino -y de manera central- no repetir las condiciones que dieron origen a esos procesos dictatoriales. Los silencios institucionales dejaron la activación de la memoria para otros ámbitos: las políticas de reparación a víctimas llevadas adelante en Chile; políticas de fomento a la actividad cultural en muchos lugares. De ese modo y de manera paralela, algunas de las "cuentas pendientes" con el pasado en el ámbito estatal quedaron relegadas, para ir resurgiendo en el futuro.

El caso argentino fue muy diferente. El énfasis estuvo puesto en el ámbito de la justicia. En el momento de la transición, una de las ideas guía centrales era que si había impunidad hacia el pasado se llevaría la impunidad hacia el futuro, con las implicancias de esto en la construcción de un Estado de derecho. En Argentina 
hubo juicios cuando en otros lugares se decretaban amnistías. Pero más allá del funcionamiento específico del aparato judicial en los casos vinculados con la represión, cabe preguntar cuál es el efecto de la instrumentación de juicios en la visibilidad social del aparato judicial y en la calidad de la institucionalidad democrática. ¿Mejora el aparato judicial en su conjunto el hecho de haber enjuiciado a los represores o de estar haciendo hoy en día juicios vinculados con la represión del pasado? Sin ninguna duda, hubo crímenes y deben ser sometidos a la justicia, lo cual permite dirimir responsabilidades y culpas. Estos juicios permiten también mostrar un sistema judicial que opera y actúa.Y eso fundamental, frente a una historia de larga data en que el Poder Judicial fue muy ajeno a la gran mayoría de la población.

Los juicios de los años ochenta tuvieron un papel fundamental en los cambios en la conciencia ciudadana y en el sistema de significados de la institucionalidad para grandes sectores de la población. Recordemos que en los países de América Latina el Poder Judicial siempre había sido un instrumento de poder de las burguesías y de los sectores dominantes. Pero, al menos en la Argentina, esto empezó a cambiar con las demandas del movimiento de derechos humanos. A comienzos de los años ochenta, cambió inclusive la espacialidad de las marchas y de las demandas sociales en la ciudad de Buenos Aires. Antes, las movilizaciones por demandas sociales y políticas de cualquier tipo -sindicales, políticas o de otro tipo- siempre iban del Congreso a la Casa de Gobierno: interpelaban al Poder Legislativo y al Ejecutivo. En el momento de la transición, las marchas y reclamos empezaron a ser triangulares, incorporando al Palacio de Justicia. Esta llegada de grupos sociales al frente del Palacio de Justicia puede ser tomada como la expresión espacializada, una metáfora espacial, de un cambio que tuvo consecuencias en términos de la incorporación del Poder Judicial como una institución ante la cual la ciudadanía podía y puede actuar para reclamar derechos.

Esta centralidad del Poder Judicial, que se mantuvo con altibajos durante treinta años, tuvo efectos de diverso tipo. Por un lado, provocó lo que algunos califican como "excesos", en el sentido de lo que ahora llamamos "la judicialización de los conflictos políticos". Frente a una multiplicidad de conflictos políticos, en vez de que los actores del mismo se sienten frente a la mesa de negociación política, la reacción es presentarlos e intentar resolverlos en los estrados judiciales, con el peligro de la sobre-judicialización de los conflictos políticos. Sin entrar a analizar la historia de los cambios en el Poder Judicial en las últimas décadas, lo que puede decirse es que esa primera instancia de juicios a los ex comandantes, realizados en 1985, tuvo un efecto cultural significativo en cuanto a la presencia de la instancia judicial como 
ámbito de reclamo de derechos ciudadanos. Pensemos, por ejemplo, en la cantidad de juicios de jubilados que se han acumulado a lo largo de los años. Son cientos de miles de jubilados que sienten que sus derechos han sido violados y que por lo tanto pueden apelar al sistema judicial. O sea, la idea de que, si se violan derechos, existe una instancia específica a la cual recurrir, es un producto cultural en cuya construcción han jugado un papel central los juicios por las violaciones a los derechos humanos durante la dictadura. Después, claro, hay que ver cómo funciona esa instancia; se puede confiar o no en la justicia. Pero la idea de que la ciudadanía tiene espacios en el Estado donde puede reclamar por sus derechos, y que el Poder Judicial es uno de esos espacios, es un aporte de los juicios de los años ochenta a la democracia, más allá del hecho específico de que se hayan juzgado y condenado a personas por esos crímenes.

Por otro lado y de manera casi especular, la centralidad del Poder Judicial implicó el movimiento opuesto, de "politización del aparato judicial": demandas y disputas acerca del reclutamiento y actuación de jueces, propuestas de "democratización" y confrontaciones entre el Poder Ejecutivo y el Judicial.

Estos no son más que ejemplos de algunas vinculaciones -inciertas, no directas o lineales -entre las maneras de elaborar respuestas al pasado reciente y la conformación de instituciones más democráticas. Otros pueden ser añadidos. Además, quedan sin responder las preguntas acerca de los efectos institucionales específicos de las "políticas de memoria”. Para ello sería necesario hacer un análisis comparativo de la calidad institucional, viendo cómo fueron aplicados los instrumentos que ahora se llaman "justicia transicional", y si eso tuvo algo que ver con lo que pasó en el desarrollo institucional posterior a los períodos de dictadura.

\section{Procesos sociales, culturales y simbólicos}

El paradigma de los derechos humanos se ha ido incorporando sólo recientemente en la vida social. Fue en los años setenta, frente a los procesos represivos de las dictaduras del Cono Sur (primero Uruguay, luego Chile y después otros países), que comenzó a extenderse la interpretación de lo que estaba ocurriendo como “violación a los derechos humanos" (Keck y Sikkink, 1998; Markarian, 2006). Hasta ese momento, y aun cuando los países latinoamericanos habían sido promotores y signatarios de la Declaración Universal de 1948, los conflictos políticos y la violencia represiva eran interpretados en clave de "ganadores" y "perdedores" antes que como "víctimas" y "victimarios". A partir de esa expansión internacional del nuevo paradigma, el encuadre de los derechos humanos, su vigencia y las condenas a las violaciones se fue tornando hegemónico. 
Hay en este punto varias cuestiones, y quiero plantear como hipótesis la de un posible desacople en la relación entre memoria y la expansión de una cultura de los derechos humanos. Parto de Argentina, donde desde mediados de la década de los setenta se forjó un movimiento de denuncia y lucha contra los crímenes que se estaban cometiendo durante la dictadura. De manera gradual pero muy sostenida, esos crímenes se fueron interpretando en la clave del paradigma de la violación a los derechos humanos. Sin ninguna duda, los derechos humanos fueron violados: torturas, desapariciones, asesinatos, privación ilegítima de la libertad, apropiación de chicos -todos ellos son crímenes espantosos, que atentan contra la vida y la integridad de las personas-. En la terminología y la normativa internacional actual son crímenes "de lesa humanidad", y no prescriben.

Ahora bien, a partir de la instalación del paradigma de los derechos humanos en los años setenta en el mundo, todo el conjunto de organizaciones y de activismo que reclama por los crímenes cometidos durante las dictaduras es caracterizado y denominado "movimiento de derechos humanos". Como consecuencia, al menos en Argentina, la expresión "derechos humanos" quedó pegada a la dictadura. Pero es sabido que la noción de derechos humanos es mucho más amplia, y la pregunta que queda abierta es bajo qué condiciones la atención prestada a la memoria de las dictaduras ayuda u obstruye la aceptación social y estatal de una concepción amplia de los derechos humanos, que incorpore una perspectiva universal de derechos civiles y políticos, pero también económicos, sociales y culturales, individuales pero también de incidencia colectiva.

Dada la intención de enfrentar e intentar resolver o mitigar los efectos y legados de las dictaduras, las políticas de la memoria societales y estatales han incluido el reconocimiento simbólico por parte del Estado, la recuperación y el señalamiento de los centros clandestinos de detención, las conmemoraciones en fechas significativas, las disputas acerca de museos, memoriales y archivos. Están también las políticas judiciales, y las económicas o de políticas sociales vinculadas con la "reparación" a las víctimas.

Aparece aquí una nueva cuestión con la noción de derechos humanos. ¿Qué incluye, además de tratar de saldar las cuentas con las víctimas de la represión y la violencia de la historia reciente? A menudo la experiencia es una disociación o segmentación, como si se tratara de dos ámbitos diferentes. Uno, el de las dictaduras; otro, que a menudo no se denomina "derechos humanos", que se liga a otras cuestiones. Reitero algo ya dicho: los derechos humanos remiten a algo mucho más amplio que las violaciones que ocurrieron en dictaduras. Son parte de la agenda de derechos humanos los derechos de los presos en las cárceles, el derecho al trabajo y toda 
la gama de derechos económicos, sociales y culturales, los reclamos de tierras de pueblos originarios, etc. Sin embargo, en el sentido común la expresión "derechos humanos" está más ligada a las memorias de la dictadura que a la situación de un chico de la comunidad indígena wichi que se muere de hambre en el Chaco. Para muchos de los/as protagonistas de las luchas ligadas a la memoria del pasado, la relación entre las memorias de la dictadura y la construcción de una cultura de los derechos humanos más amplios no es el tópico dominante; lo dominante es el reclamo por más y más políticas de memoria. Pocas veces se amplía el campo de demandas para vincular unas y otras.

En este punto, además, es importante mirar la temporalidad de los fenómenos a los que nos estamos refiriendo. Hay un tiempo "corto" de las dictaduras y la violencia y la transición posterior, período en el que estamos inmersos/as ahora. Y hay un tiempo "largo" de conformación de estructuras sociales e históricas, donde las desigualdades de poder, las discriminaciones y exclusiones ocupan otros lugares. Cuando se estudian las memorias de grupos específicos, aparece la condensación del tiempo largo y el tiempo corto; hay memorias de larga duración y memorias más cortas, y están interrelacionadas. En su estudio sobre las memorias de la última dictadura en comunidades del norte de la Argentina, Ludmila da Silva Catela trabajó las ideas de memoria larga y memoria corta (da Silva Catela, 2007). Esta cuestión está también presente en el trabajo de Theidon (2007) sobre las memorias de las mujeres en comunidades indígenas del Perú. En el trabajo etnográfico en este tipo de comunidades, la dictadura, la represión y la violencia del pasado reciente se superponen con discriminaciones y violencias estructurales de muy larga data, lo cual hace que el pasado reciente sea interpretado en claves de más larga duración. Otro ejemplo reciente, en otro contexto, es el de Japón y el tsunami, el terremoto y la fuga radiactiva. Mi pregunta es, ¿cuál es el lugar de la memoria de Hiroshima en la vivencia actual de la población japonesa de Fukushima? Sin duda, las vivencias y las memorias de Hiroshima están presentes en las experiencias vividas después.

Este tipo de preguntas son las que se hace quien mira la realidad en un momento dado con una perspectiva de memoria y de historia. Al respecto, recordemos lo que dice el prefacio del informe de la Comisión Verdad y Reconciliación del Perú:

De cada cuatro víctimas, tres fueron campesinos o campesinas cuya lengua materna era el quechua. Se trata, como saben los peruanos, de un sector de la población históricamente ignorado por el Estado y por la sociedad urbana, aquella que sí disfruta de los beneficios de nuestra comunidad política. La Comisión no ha encontrado bases para afirmar, 
como alguna vez se ha hecho, que éste fue un conflicto étnico. Pero sí tiene fundamento para aseverar que estas dos décadas de destrucción y muerte no habrían sido posibles sin el profundo desprecio a la población más desposeída del país, evidenciado por miembros del PCP-Sendero Luminoso y agentes del Estado por igual, ese desprecio que se encuentra entretejido en cada momento de la vida cotidiana de los peruanos (Comisión de la Verdad y Reconciliación, 2003:1-2).

Cuando hoy hablamos de memoria, estamos hablando de memoria del sufrimiento, de la dictadura, de las violaciones a los derechos humanos, de la criminalidad del régimen, etc., etc., y las memorias que se rescatan y que los actores reivindican son memorias de esas situaciones límite. La pregunta que queda en el aire es: más allá de las propias víctimas, ¿para quién son importantes estas memorias?¿Qué recordar del pasado para construir qué tipo de régimen, qué tipo de institucionalidad democrática? ${ }^{1}$

La generalización del paradigma de los derechos humanos tiene otra implicancia: la centralidad de la víctima. Esto lleva a una creciente presencia de demandas anclada en la autoidentificación como víctimas, a una tendencia a la victimización. Ser víctima parece dar derechos -a los perpetradores, como es el caso de los militares argentinos, o a los políticos que se quejan por la manera en que son tratados por los medios.

Recordemos que definirse como víctima implica al mismo tiempo desestimar la capacidad de acción como sujeto, y esto presenta una paradoja entre la victimización presente en el paradigma de los derechos humanos y las demandas en clave ciudadana. Visto en perspectiva excluyente, parecería que al hablar desde la ciudadanía, una estuviera negando el dolor, el sufrimiento o la violación de los derechos.

\section{Sentido educativo y pedagógico de la memoria y la transmisión. ¿A quiénes? ¿De qué?}

Niños y jóvenes, con sus maestros/as y a veces con guías especializados, visitan sitios de memoria, memoriales y museos especializados. Se ven los grupos, de diversas

\footnotetext{
Vinculando este punto con el anterior sobre cambios institucionales, cabe recordar que en las últimas décadas, las reformas constitucionales de los países de la región han reconocido muchos "nuevos" derechos, ligados a discriminaciones y desigualdades históricas y estructurales, especialmente los derechos de los pueblos originarios. En estos cambios, ¿tuvieron algún papel las memorias de las dictaduras y las violencias? ¿O fue el producto de cambios en el clima internacional y en la correlación de fuerzas políticas internas a cada país? Además, la pregunta es si los cambios normativos se manifiestan en las prácticas estatales (políticas dirigidas a revertir desigualdades) y en las prácticas sociales (discriminación étnica y de género, entre otras). Estas son cambios que apuntan a más democracia, pero ¿tiene que ver la memoria del pasado reciente en esta implementación?
} 
edades. En Auschwitz o en Sachsenhausen hay grupos escolares de diversas edades se ven los de 8-10 años; también los de 15-16. Caminan, paran en algún lugar donde reciben alguna explicación, y siguen. Como todo grupo infantil, algunos están cerca de sus instructores y escuchan lo que se les dice. Otros se distraen, juegan entre ellos, miran para otro lado - todo lo esperable en grupos infantiles y de adolescentes-. No sabemos qué pasa antes o después: con qué preparación llegan a la visita; cuánto de lo que se les muestra o ven por sí mismos es discutido, analizado, problematizado antes de la visita o al regresar al aula. Las "explicaciones" que se escuchan en el lugar del hecho son, en realidad, descripciones literales posibles de lo que se hacía en cada lugar del campo o sitio: "aquí, en estas barracas, vivían los prisioneros"; "había lugar para XX pero hubo momentos en que vivían -si así se puede llamar - tres, cinco o cincuenta veces más". "Los baños no alcanzaban", "la comida era escasísima”, "se los despertaba a tal hora y tenían que formar fila". Las descripciones son del horror. No parece haber lógica o racionalidad de la acción que pueda ser transmitida. Se trata de relatos del horror, donde había villanos y víctimas...

Mirando esas escenas, viendo a los chicos correteando en la entrada al campo de Auschwitz de la misma manera en que corretean en un día de campo o en una visita al zoológico, la pregunta se impone: ¿para qué? ¿cuál es el sentido pedagógico de la visita? ¿Es un ritual, muchas veces repetitivo, parecido a izar la bandera en la escuela, o cantar el himno?¿Es enseñanza de la historia? Se trata de un propósito de formación cívica, de contribuir a la formación de ciudadanos/as solidarios/ as, responsables, democráticos/as? No es el propósito de esta sección del artículo participar en el debate sobre el para qué enseñar historia; tampoco en los debates sobre la relación entre verdad y narración. Más bien, el objetivo es entrar al tema desde diversos programas y proyectos extracurriculares o extraescolares, ligados a los sitios de memoria o a programas de extensión, no desde la enseñanza de la historia reciente en el currículo escolar. ¿Visitas o paseos? Preparar materiales educativos, ¿de qué tipo?, ¿para qué?

Hay diversos modelos o propuestas, implícitos y explícitos, en estos programas. En un primer modelo, el énfasis está puesto en transmitir información sobre lo ocurrido, partiendo del supuesto de que si se sabe qué pasó, esto incide directamente en la "formación" (democrática, ciudadana, cívica, u otras denominaciones) de los sujetos. "Recordar para no repetir" significa armar un relato fáctico de lo ocurrido y transmitirlo. En los períodos post violencia, después de las catástrofes sociales, cuando la magnitud y naturaleza de lo ocurrido todavía no están sistematizadas o encuadradas en una narrativa con sentido, se requiere una etapa de organización de 
datos fácticos, de elaboración de un relato de lo ocurrido. Paso previo a cualquier estrategia de transmisión. Cartillas, películas documentales y de las otras, clases alusivas, fascículos, cronologías, etc., son los vehículos que se eligen para este fin de transmitir información. Muchas visitas guiadas a sitios de memoria (ex campos de concentración o de detención) organizan los recorridos siguiendo de manera lo más literal posible el patrón de "lo ocurrido".

La relación entre información y orientación o práctica ciudadana, sin embargo, no es lineal o directa. La pedagogía contemporánea lo sabe. En consecuencia, cada vez más, la estrategia de transmisión anclada en la información es complementada o aun reemplazada por otra que promueve la reflexión, y que recibe-según el programa del que estemos hablando- nombres tales como "reflexión crítica", "memoria democrática", "memoria histórica", "procesos autónomos locales y regionales de esclarecimiento de la verdad y construcción de las memorias", etc. Todos estos programas tienen una idea subyacente compartida: el "deber de memoria", el convencimiento de que existe un imperativo moral o deber cívico de recordar el horror y que ese recuerdo -mediado ahora por la capacidad reflexiva de los sujetos — es un antídoto para prevenir violencias y horrores futuros. Y hay todavía algo más: que esa memoria y esa obligación moral de alguna manera aseguran la formación de ciudadanos y ciudadanas con convicciones y prácticas democráticas. Veamos algunos ejemplos:

Desde el momento de su formación en 1999, la Comisión Provincial de la Memoria de la Provincia de Buenos Aires se propuso tareas educativas y de transmisión ${ }^{2}$. Inicialmente, éstas consistieron en la elaboración de fascículos informativos, organizados cronológicamente, sobre el régimen militar en Argentina y sobre la transición. En el momento de su elaboración, la mayor parte de los y las docentes habían vivido durante la dictadura, por lo cual tenían alguna experiencia personal sobre el tema. Años después, las nuevas cohortes de docentes necesitan saber qué pasó porque no tienen esa experiencia vivida. Por eso, señala Sandra Raggio, en términos de su utilidad pedagógica, quizás estos materiales tengan más utilidad ahora que hace quince años.

A lo largo de los años siguientes, el programa fue cambiando de objetivos y orientación. La escuela (secundaria) sigue siendo el lugar de conexión con el programa, pero los objetivos y las actividades propuestas son muy diferentes. Hoy

2 Agradezco a Sandra Raggio, directora del Programa Jóvenes y Memoria de la Comisión Provincial de la Memoria de la Provincia de Buenos Aires su disposición a ser entrevistada y a compartir su experiencia en dicho programa. La información sobre el Programa que ella brindó fue complementada con la información en el portal y en publicaciones de la Comisión. Sus reflexiones sobre lo hecho ayudaron enormemente en la elaboración de esta parte de este artículo. 
en día el programa intenta centrarse en los estudiantes y no tanto en el o la docente narrando la historia reciente. Su propuesta se titula "Los desafios de la democracia en las luchas por la igualdad, la memoria y los derechos humanos". La pregunta a la que apunta es cómo generar en la escuela un lugar ligado a la comunidad local, que recupere y trabaje sobre las cuestiones del pasado dictatorial, pero también sobre la vigencia de los derechos humanos en la actualidad. Como son los propios jóvenes quienes elaboran sus propuestas, los proyectos pueden incluir temas ambientales o la violencia policial hacia los jóvenes. La experiencia indica que en este programa de muy vasta escala (participan unos 10.000 estudiantes por año) los estudiantes enlazan el pasado y el presente de modos diversos, y encuentran vínculos inesperados. La justificación del programa está en su portal:

Recordamos para el futuro, convencidos de la enorme potencialidad de la escuela para los trabajos de la memoria. El punto de partida no fue sólo el mandato de recordar como imperativo ético de la educación en tiempos de democracia, sino el reconocimiento del derecho a la memoria de las nuevas generaciones. Es decir, la escuela no como vehículo para la transmisión de un legado sino como espacio para la apropiación de las experiencias pasadas. No se trata de hacer repetir a los jóvenes el relato de los mayores, sino que puedan reelaborarlos, tamizándolos en la trama de su propia experiencia. (...)

No se trata sólo de una propuesta novedosa para enseñar historia, sino sobre todo de una intervención política para promover un trabajo sobre el pasado que logre ampliar los marcos de la memoria social, incorporando las preguntas (y las respuestas) de las nuevas generaciones (Portal del Programa Jóvenes y Memoria, Comisión Provincial por la Memoria de la Provincia de Buenos Aires; resaltado mío). ${ }^{3}$

Esta preocupación por incorporar la "apropiación", la reflexividad y el papel activo por parte de los y las jóvenes, y de los visitantes en centros clandestinos de detención de manera más amplia, como estrategia de transmisión -antes que en una imagen más cercana a la de una correa de transmisión mecánica- prevalece en muchos otros programas y propuestas, al menos en sus propuestas explícitas:

La marcación progresiva de los más de 500 ex centros del horror en todos y cada uno de los lugares del país donde se desplegaron, se propone interpelarnos como sociedad, promover la reflexión crítica e incentivar

http://jovenesymemoria.comisionporlamemoria.net (recuperado el 4/10/2013). 
la construcción de memorias democráticas que tengan en cuenta la historia y las experiencias de nuestro pasado reciente y sus vinculaciones con el presente (Portal de la Secretaría de Derechos Humanos de Argentina; resaltado mío). ${ }^{4}$

En otros países, las propuestas son presentadas de manera análoga. En Colombia, por ejemplo, se propone "La caja de herramientas":

... una herramienta pedagógica que ofrece instrumentos conceptuales, metodológicos, éticos y psicosociales para que desde distintas voces y lugares de la sociedad, se impulsen procesos autónomos locales y regionales de esclarecimiento de la verdad y construcción de las memorias. Está dirigido a personas interesadas en formarse como gestores de memoria que pueden ser hombres y mujeres con liderazgo en sus comunidades, maestros, funcionarios, periodistas, jóvenes y trabajadores culturales. El propósito de este material ... es ofrecer herramientas para reconstruir memoria histórica que permitan explorar y entender modos de empoderamiento de las voces silenciadas, subordinadas y suprimidas en el ámbito de la memoria recogiendo sus experiencias como víctimas de vejaciones específicas, pero también como actores sociales y políticos con capacidad transformativa (Centro de Memoria Histórica de Colombia; resaltado mío). ${ }^{5}$

Esta revisión podría seguir con numerosos otros portales y proyectos, ya que es notoria la proliferación de propuestas pedagógicas que promueven recuperar o "construir" memorias, ancladas en pasados de violencia y represión, para ligarlas con las experiencias del presente. La terminología y adjetivación varían: "memorias democráticas", "memoria histórica", "memoria social" o "memorias silenciosas". Hay en ellos una intención formativa donde se espera que la capacidad reflexiva sobre el pasado que se promueve ayude a la "formación ciudadana" de los/as jóvenes. En la

http://www.derhuman.jus.gov.ar/anm/sm señalizac.html (recuperado el 4/10/2013).

5 http://www.centrodememoriahistorica.gov.co/index.php/informes-gmh/informes-por-temas/ metodologica-y-conceptual (recuperado el 4/10/2013).

6 El set didáctico para docentes "Construyendo Memorias" del Museo de la Memoria y los Derechos Humanos de Santiago, Chile “... busca mediar entre memorias silenciosas en la ciudad y la significación que hagan los jóvenes a través de su activo trabajo de investigación. Unir el pasado con experiencias personales y colectivas, es en sí mismo un acto ciudadano, que contribuye a la formación de un juicio propio e interpretación de la historia reciente para aprender de ella fortaleciendo actitudes democráticas" (resaltado mío). http://www.museodelamemoria.cl/educacion/materialpara-docentes/ (recuperado el 4/10/2013). 
práctica, es notorio cómo cuando se deja intervenir a los jóvenes, o a los otros que no son víctimas, en la formulación de sus propios relatos y en la formulación de sus propias interpretaciones de lo que significan las violaciones a los derechos humanos, las referencias a la violencia y a las dictaduras pueden ocupar un lugar secundario, y cobran centralidad las experiencias propias y otros ámbitos - personales, locales, comunitarias-de las demandas por derechos.

La pregunta es inevitable y queda todavía sin respuesta: ¿qué sabemos sobre estas relaciones entre pasado y presente/futuro? ¿Entre saber algo sobre los horrores y la construcción de una democracia cotidiana en el hoy y en el mañana?

\section{Para terminar}

Está claro, al final de este breve recorrido, que hay más preguntas que respuestas. Implícito en lo planteado hay en realidad una agenda de investigación para seguir poniendo en cuestión estos temas. Para hacerlo, quizás convenga tener presentes algunos puntos.

En primer lugar, la importancia de historizar las memorias, de mirar la historia de las memorias a lo largo del tiempo y no las memorias tomadas como sentidos cristalizados. Hay una historia de los procesos institucionales y de los procesos simbólicos. Esta historia no es azarosa sino que cada etapa y cada coyuntura implican abrir nuevas oportunidades; también cerrar u obturar otros procesos. En el plano pedagógico propiamente dicho, algunos de los programas revisados hablan de "construcción de memorias", lo cual supone pluralidad de visiones y posibilidades de apropiaciones diversas. Esto está en el modelo y en la propuesta, pero no siempre se cumple en la práctica -especialmente cuando se da simultáneamente el predominio de un "deber de memoria" con un relato único o dominante.

Es sabido que no hay una memoria única, sino que distintos actores y distintas generaciones diferirán en el sentido que le dan al pasado. Hay también diversos pasados, cortos y acotados (regímenes dictatoriales establecidos con un calendario político centrado en los “acontecimientos”) para algunos procesos que se desarrollan en un tiempo más largo para otros. A su vez, el énfasis en el "pasado reciente" puede opacar violencias y discriminaciones en pasados anteriores o en condiciones estructurales. De ahí la necesidad de mirar las memorias de corto plazo en un marco temporal mucho más largo.

El pasado es un objeto de disputa, donde actores diversos expresan y silencian, resaltan y ocultan, distintos elementos para la construcción de su propio relato. 
Lo que encontramos es una lucha por las memorias, lucha social y política en la que se dirimen cuestiones de poder institucional, simbólico y social. A su vez, los fenómenos de memoria se manifiestan en distintos planos de la vida social: el plano institucional, el cultural, el subjetivo. Si bien en este trabajo se presentaron algunos "pantallazos" de esta multiplicidad de planos diferenciando los procesos institucionales, simbólico-culturales y educacionales, el desafio para la investigación es también el estudio de sus convergencias e interrelaciones.

Una palabra final: quienes actúan en función de un "deber de memoria" normalmente tienen UN relato y una interpretación del pasado, y es esa versión la que quieren transmitir a quienes no tuvieron la experiencia o no comparten la interpretación dada. Llevada a su extremo, esta postura puede contradecir los objetivos pensados hacia el futuro -la construcción de una ciudadanía activa, comprometida con la esfera pública y con convicciones democráticas-. La paradoja planteada es entre una transmisión unívoca y una reflexividad y activismo ciudadano que, para que lo sea, no puede ser programado. En suma, cuestionar el supuesto de la relación directa y lineal entre memorias y democracia implica reconocer la complejidad de la realidad socio-política y reconocer también la incertidumbre.

\section{Referencias bibliográficas}

Aguilar Fernández, Paloma (1996). Memoria y olvido de la Guerra Civil Española. Madrid: Alianza.

Comisión de la Verdad y Reconciliación (2003). Informe Final de la Comisión de la Verdad y Reconciliación. Lima: Comisión de la Verdad y Reconciliación.

Da Silva Catela, Ludmila (2007). "Poder Local y Violencia: Memorias de la Represión en el Noroeste Argentino”. En Isla,Alejando (editor). En Los Márgenes de la Ley: Inseguridad y Violencia en el Cono Sur. Buenos Aires: Paidós Tramas Sociales.

Keck, Margaret y Kathryn Sikkink (1998). Activists Beyond Borders. Ithaca: Cornell University Press.

Markarian,Vania (2006). Idos y recién llegados: La izquierda uruguaya en el exilio y las redes transnacionales de derechos humanos, 1967-1984. Montevideo: Correo del Maestro.

Theidon, Kimberly (2007). "Gender in transition: common sense, women and war", en Journal of Human Rights, Vol. 6, Nº4, pp. 453-478. 